\title{
A Two-Step Water-Management Approach for Nuclear Power Plants in Inland China
}

\author{
Xiaowen Ding ${ }^{1,2,3,} *$ Wei Wang ${ }^{3, * *}$ Guohe Huang ${ }^{1,2,} * * *$ \\ 1. Key Laboratory of Regional Energy and Environmental Systems Optimization, Ministry of Education \\ North China Electric Power University, No.2, Beinong Road, Beijing 102206, China \\ 2. Institute for Energy, Environment and Sustainable Communities, University of Regina \\ 120, 2 Research Drive, Regina, Saskatchewan S4S 7H9, Canada \\ 3.Research Center for Beijing Energy Development, North China Electric Power University, No.2, \\ Beinong Road, Beijing 102206, China \\ **E-mail:wwfancy@163.com \\ ***E-mail: huangg@uregina.ca
}

Qingwei Chen
Water Resources Management Centre, Ministry of Water Resources, No.10, Nanxiange Street, Beijing, 100053, China
E-mail: chenqw@mwr.gov.cn

Guoliang Wei

Nuclear and Radiation Safety Centre, Ministry of Environmental Protection, Beijing 100082, China

E-mail: weiguoliang78@163.com

Received 9 May 2014

Accepted 27 August 2014

\begin{abstract}
Nowadays, effective management of water withdraw, water consumption and wastewater discharge is desired for nuclear power plants in inland China. In this paper, the inland nuclear power industry and its policies in China were reviewed, a two-step water-management (TSWM) approach for the plants was proposed. The framework includes the flow process, main tasks, and tools of TSWM management for any nuclear power plant in inland China. Finally, suggestions on future development of the management were also put forward.
\end{abstract}

Keywords: Two-step water-management; water resources assessment; nuclear power plant; inland China

\section{Introduction}

Due to economic development and population growth, energy demands are increasing greatly in many countries across the world. At the same time, various energy activities based on fossil fuels lead to the emission of a tremendous amount of greenhouse gases (GHG), which is considered as the primary contributor to climate change (Barrie, 2011; Wang and Sun, 2012). To deal with reliable energy supply and GHG emission

\footnotetext{
*Corresponding author: binger2000dxw@hotmail.com.
} 
mitigation, governments around the world have implemented a series of energy-related strategic policies of which new energy (particularly nuclear power) exploitation is probably the most direct and effective one (Sovacool, 2008; Jasmina et al., 2012). As for nuclear power utilization, inland nuclear power plants (NPPs) have been developed in 14 countries including the USA (Bezdek, 2009), France (Kopytko and Perkins, 2011), Canada (Lane et al., 2013) due to limited ideal coastal sites. Moreover, NPPs are also planned to be constructed in several developing countries including China (Ma et al., 2010). However, fresh water consumption (Khamis and Kavvadias, 2012) and radioactive wastewater discharge (Nuclear Energy Institute, 2009) of inland NPPs are major issues which have attracted high attention, particularly under accident conditions (International Atomic Energy Agency (IAEA), 2011). For example, huge water consumption is becoming the most important factor to decide on the survival of inland NPPs in China (Zai, 2012). More importantly, surface water is the main source of drinking water in many countries (Zhang et al., 2011). So management of water withdraw, water consumption and wastewater discharge for inland NPPs based on its quantitative assessment are crucial to not only water resources utilization and conservation but also sustainable development of inland nuclear power industry.

Researches on water resources management for inland NPPs have been carried out by several countries such as the USA, France, Canada and China. As for water withdraw, it was proposed that the amount of an inland NPP adopting AP1000 (Advanced Passive Pressurized Water Reactor 1000) technology was between 0.96 and $1.27 \mathrm{~m}^{3} / \mathrm{s} \cdot \mathrm{GW}$ (United States Nuclear Regulatory Commission (USNRC), 2009; Changjiang Water Resources Commission (CJWRC), 2009; Wuhan University, 2009a; Wuhan University, 2009b). In the USA, USNRC (1984) required that an assessment of the impact on the flow of the river, instream and riparian ecological communities must be carried out if an inland NPP withdrew make-up water from a river whose annual flow rate was less than $9 \times 10^{10} \mathrm{~m}^{3} / \mathrm{y}$. With respect to water consumption, Khamis and Kavvadias (2012) presented that inland NPP generally consumed 20 to $83 \%$ more of water comparing with that based on coal and at the same capacity. The amount for an inland plant was regarded as approximately 35 to 65 million litres per day depending on the types of reactors (Khamis and Kavvadias, 2012). Moreover, some reference standards rather than compulsory requirements also have been developed. For example, Parliament of Australia (2006) suggested the maximum amount of cooling water consumption for an inland NPP as $0.76 \mathrm{~m}^{3} / \mathrm{s} \cdot \mathrm{GW}$. Besides water withdraw and consumption, much more efforts were made to control wastewater discharge. In the USA, USNRC (1998) required that wastewater discharge of NPPs should comply with the requirements of Clean Water Act as well as the regulations issued by United States Environmental Protection Agency, USNRC and local governments. USNRC (2011a) developed a liquid effluent release standard which included three levels of dose limits to individual members (i. e. 3, 25 and 100 mrem per year). Such requirements were also developed in France (Nuclear Safety Authority of France, 2006), Canada (Canadian Nuclear Safety Commission, 1997), China (Ministry of Environmental Protection of the People's Republic of China (MEPPRC), General Administration of Quality Supervision, Inspection, and Quarantine of the PRC (GAQSIQPRC), 2011a; 2011b). In the mean time, wastewater discharge control in successive dry seasons and water conservation in the emergency condition were also improved by countries (Nuclear Safety Authority of France, 2006) and international agencies (IAEA, 1986a; 1986b; 1994). However, such water resources assessment of NPPs were mainly based on a one-step approach such as environmental impact assessment (EIA) (Department of Justice Canada, 2012) or radioactive effluent release assessment (USNRC, 2011b) which emphasized on wastewater discharge control but ignored water withdraw and consumption. In fact, for countries with huge population and various water users, more effective approaches are desired considering their serious conflicts between water supply and demand. Such approaches should be able to tackle these water conflicts through decomposing various impact factors into detailed issues that are of practical implications. However, there have no published reports on it. Therefore, in this research, a two-step watermanagement (TSWM) approach will be proposed to address the issues of water conflicts, where various impact factors will be decomposed into phases of EIA and water resources assessment (WRA).

The EIA will be useful for assessing the possible 
impacts that inland nuclear power plants may have on the environmental (soil, land use, water quality, air quality, noise environment, etc) biological, social and economic aspects. Moreover, the WRA will help to obtain reasonable and feasible water-related schemes for inland NPPs. The EIA will be the basic step in which water resources is considered through assessing the impacts of wastewater discharging on local water quality. Subsequently, the WRA will be advanced as a secondary assessment procedure which focuses on water resources exclusive, and more important, WRA includes whole water-related processes (i.e. water withdraw, water consumption and wastewater discharge) and concerns both water quality and water quantity. Therefore, as an extension of the previous efforts on water resources management, a management framework of the TSWM approach for NPPs in inland China is to be proposed. Rationalities of water withdraw, water consumption and wastewater discharge of NPPs, as well as the associated impacts are to be evaluated. The major procedure, tasks and approaches are to be discussed, as well as the completing requirements of TSWM reports for China's inland NPPs. As a result, a series of suggestions for advancing water resources management for nuclear power plant in inland China will be presented. This research is also expected to provide a reference for countries such as India, Pakistan who are operating or planning to construct inland NPPs and with problems of population explosion and water shortage.

\section{The Development of Inland Nuclear Power Industry in China}

According to the Medium and L ong-term Development Plan of N uclear P ower ( 2005 to 2020) approved by China's State Council, the capacity for nuclear power generation will have reached $40 \mathrm{GW}$ by 2020 and will have approximately accounted for $4 \%$ (i.e., 260 to 280 billion $\mathrm{kWh}$ ) of the total generated electricity in China (National Development and Reform Commission of the PRC (NDRCPRC), 2007). Due to limited land resources in coastal areas and the increasing electricity demands, siting of NPPs has extended to inland China. In February 2008, NDRCPRC identified Hunan Taohuajiang NPP, Hubei Dafan NPP and Jiangxi Pengze NPP (Yang and Huang, 2010) as the three pioneering NPPs to develop nuclear power industry in inland China. The central government has thus identified sites, construction units, and the associated preliminary works for each NPP. In March 2008, NDRCPRC and National Energy Administration of the PRC (NEAPRC) proposed that the Medium and Longterm $D$ evelopment $P$ lan of $N$ uclear $P$ ower (2005 to 2020) should be modified and the proportion of nuclear power to the installed total capacity would have been over 5\% by 2020 (Wang, 2009). In December 2009, the Second National Energy Conference was held in which nuclear power industries in inland China were proposed to be booming in the next 5 to 20 years. Nuclear energy development in inland areas of the country was shifted from active to aggressive states (Zhou and Zhang, 2010). Up to June 2010, preliminary feasibility reports of the 31 NPPs in inland China had been approved (Dai and Yi, 2010; Table 1 and Figure 1). In January 2011, China Energy Conference was held in which the three pioneering NPPs were suggested to be constructed during the period of "the $12^{\text {th }}$ Five-Year" (i.e. 2011 to 2015). At the same time, many other inland provinces have already carried out preliminary works of nuclear industry development, such as Anhui, Jilin, and Henan provinces (Yan et al., 2011).

On March $11^{\text {th }}$, 2011, due to the M 9.0 earthquake, one of the most serious nuclear accidents in history occurred in the Fukushima Dai-ichi NPP, Japan (Nuclear Accident Independent Investigation Commission, 2012). On March $16^{\text {th }}$, 2011, China's State Council made a decision that no NPPs should be approved until the $12^{\text {th }}$ Five-Year Plan and 2020 Vision of Nuclear Safety and Radioactive Pollution Prevention and C ontrol (i.e., Nuclear S ecurity Plan) have been confirmed (China's State Council, 2011), indicating that China attaches great importance to security and stability of its nuclear industry. Especially for any NPPs in inland China, considering that the AP1000 is a new technology without operating practice, security is considered as the most important factor. By the end of 2011, earthworks of the three pioneering NPPs in inland China had been completed. Site analysis of NPPs had been carried out in more than 10 provinces in China (Zhang et al., 2011). In $2012 R$ eport on $t$ he Government's Work (Wen, 2012) and President Jintao Hu's speech at 2012 Seoul Nuclear Security Summit (Hu, 2012), China's nuclear power industry was presented to be developed in a security and sustainable way in the near future. On October $16^{\text {th }}, 2012$, Nuclear Security Plan was formally proposed by the MEPPRC, NDRCPRC, the Ministry of Finance of the PRC, 
Table 1. Nuclear power plant projects in inland China (up to June, 2010).

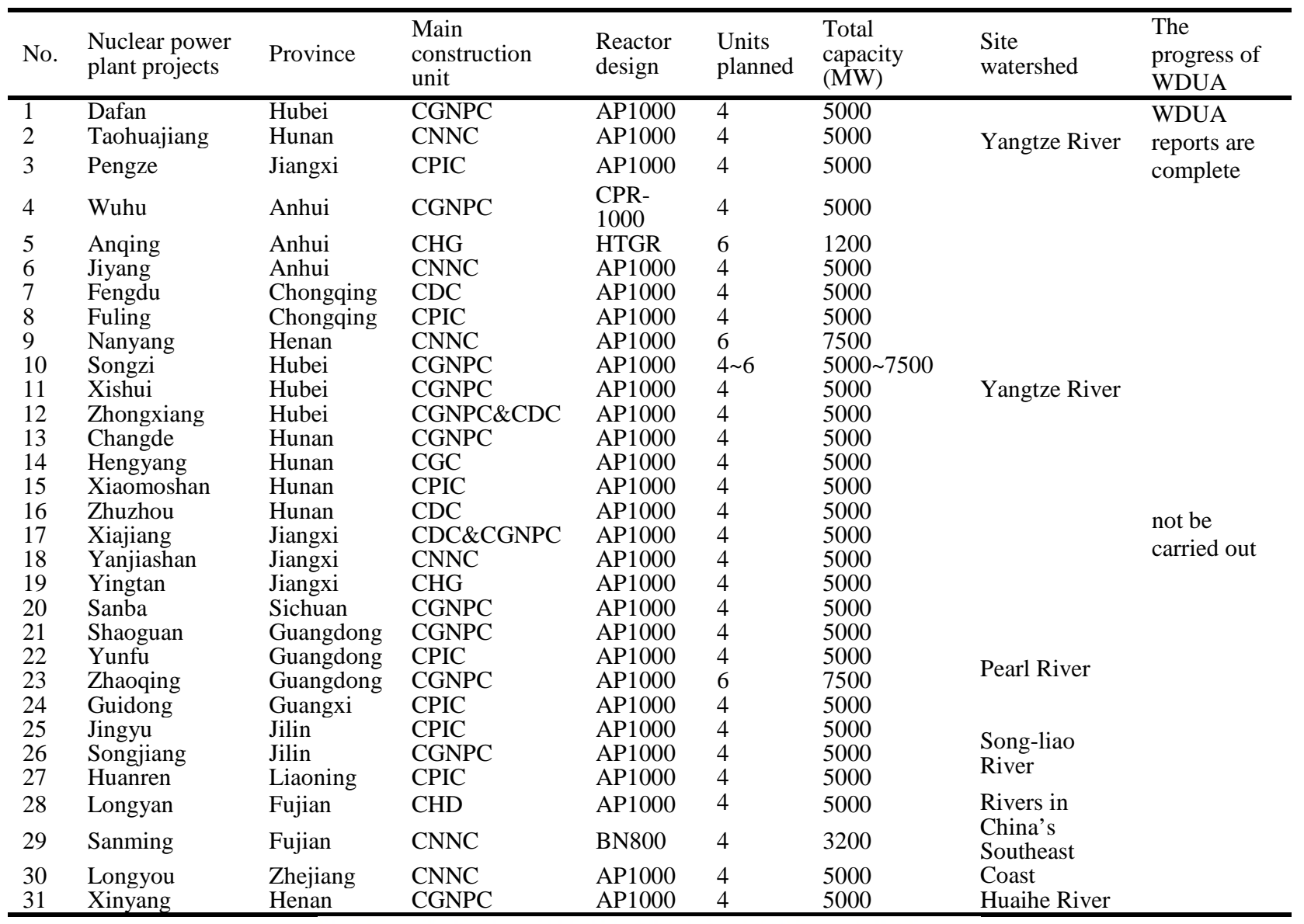

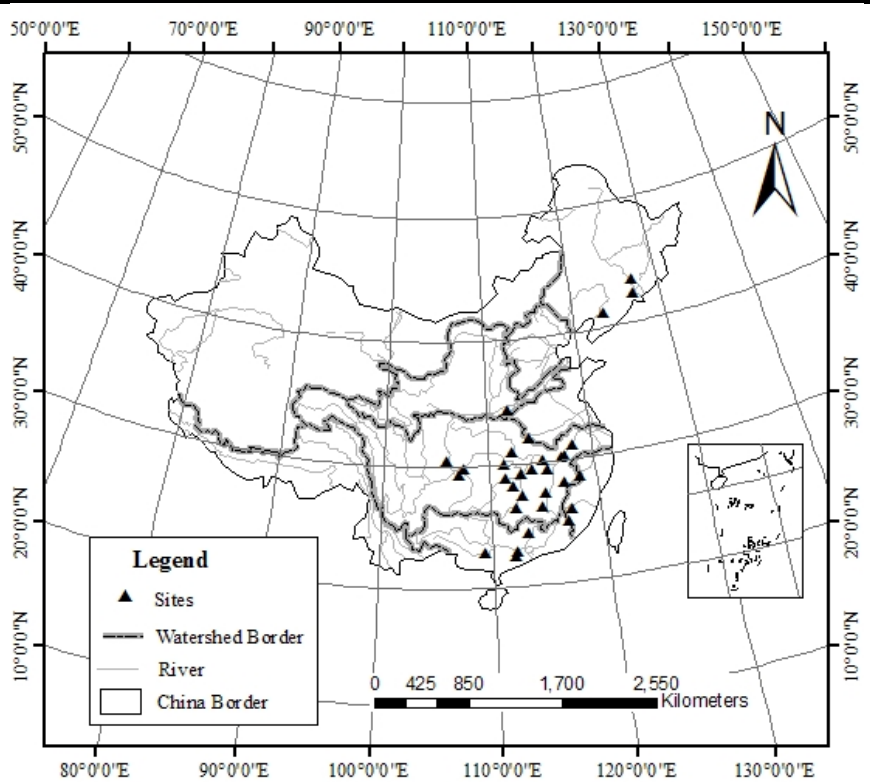

Fig. 1. Distribution of nuclear power plants in inland China that have passed preliminary feasibility studies.

NEAPRC, and Administration of the Defence Science and Technology Industry (MEPPRC, 2012). On October $24^{\text {th }}, 2012$, China issued Nuclear P ower Saf ety P lan (2011 to 2020) as well as the Medium and Long-term 
Development P lan of N uclear P ower (2010 to 2020), and decided to resume the construction of NPPs (Zhong, 2012).

\section{Complexities of Water Resources Assessment Related to Inland Nuclear Plants}

Inland NPPs, a whole new kind of power plant in China, the construction of which hasn't been approved up to the present considering the complexities of their waterrelated issues. The most important concerns are huge water consumption and low-level radioactive wastewater discharge under normal working conditions. Other major considerations are large quantities of water needed for cooling and middle even high-level radioactive wastewater discharge under accident conditions. Besides the characteristics of water withdraw, consumption and discharge of inland NPPs, national conditions and water resources conditions of China exacerbate the complexities of water-related issues of inland NPPs.

Firstly, China, with the largest population in the world, has a considerable conflict between water supply and demand. Especially for the site areas of inland NPPs, there are intensive municipal, industrial, agricultural intakes in site watershed, which makes the assessment of water withdraw and consumption critical. Some of the watersheds almost have reached the limits of water resources development and utilization (Zhou, 2009). However, the operation of a NPP really consumes large amount water for cooling. Therefore, huge water consumption becomes a crucial factor to decide on the survival of inland NPPs in China (Zai, 2012). Secondly, for more convenient water withdraw and wastewater discharge, sites of inland NPPs are likely to be close to inland water bodies. Different levels of radioactive wastewater under normal working conditions and accident ones would be discharged into the nearby rivers, lakes and reservoirs. More important, different from other countries who have developed inland nuclear power industry (e.g. France), China, with high degree correlation of river networks, takes surface water as the predominant drinking water source, especially for inland NPP site areas where surface water is abundant and closely related to inland NPPs. A balanced solution is called for to resolve the conflict between radioactive wastewater discharge and the conservation of drinking water source considering that there are many drinking water sources in site watersheds and their downstream.
Therefore, not only water quality but also water quantity of discharged wastewater should be assessed and a series of drainage schemes under different conditions should be proposed subsequently. Thirdly, even though the probability of a nuclear accident is as low as $10^{-}$ 5/unit year (USNRC, 1990), the supply of huge accident handling water and the impacts of radioactive wastewater discharge on receiving water bodies must be careful deliberated. The amounts of accident handling water and the methods of water supply for possible nuclear accidents should be fully considered. Furthermore, the effects of middle even high-level radioactive wastewater discharge under accident conditions on site watersheds, especially for local and downstream drinking water sources, should be assessed quantitatively.

Nowadays, China's each construction project is required to carry out EIA which merely focuses on wastewater discharge control as far as water resources is concerned. However, it is insufficient for inland NPPs considering the complexities of water-related issues for nuclear power plant in inland China. In addition, AP1000 adopted by NPPs in inland China is a totally new technology without any operating practice in the world. Therefore, a two-step approach is demanded to address these complexities. In other words, WRA needs to be conducted following EIA to assess the whole water water-related processes of inland NPPs and to propose the feasible schemes. According to current nuclear power policies, the three pioneering NPPs may be constructed during the period of the $13^{\text {th }}$ Five-Year (i.e., the years from 2016 to 2020). Considering that WRA approval is a legal process before the construction of any NPPs, WRA management system for it should be constructed initially before the beginning of the $13^{\text {th }}$ Five-Year. Therefore, WRA of inland NPPs is an innovative but urgent work in China. In the following, the article tentatively put forward a management framework of TSWM for NPPs in inland China in order to promote the establishment of the system.

\section{Development of Two-step Water-management Approach for Nuclear Power Plants}

A management framework of the TSWM approach for NPPs in inland China is to be proposed. The first step is EIA, which has been developed for NPPs in China. The further step is WRA, which is required by Management Approaches of Water-draw and Utilization Assessment 
of Construction Projects and Guidelines of Water-draw and $U$ tilization A ssessment for $C$ onstruction $P$ rojects (Trial) but is still in the stage of management framework construction. Therefore, the major procedure, tasks and approaches are to be presented and discussed. Furthermore, the completing requirements of assessment reports for China's inland NPPs are also to be proposed.

\subsection{Flow process of two-step water management}

The flow process of TSWM for NPPs in inland China should include: (a) initially, implementing EIA management for a inland NPP, (b) secondly, carrying out WRA with the beginning of the construction unit entrusting a qualified agency, (c) the qualified agency drafting an outline of the WRA report completion, (d) the related watershed authority approving the outline and providing necessary comments, (e) the qualified agency carrying out the assessment and completing report based on the outline and comments, (f) the construction unit submitting a application to the watershed authority with the required documents, (g) the watershed authority approving the report preliminarily, providing basic comments, and submitting the documents to Ministry of Water Resources of the PRC (MWRPRC) for administrative approval, (h) MWRPRC reviewing the application documents and making a decision for acceptance or rejection, (i) MWRPRC organizing site survey and holding a hearing in the site if the application is accepted, (j) review committee reviewing the report and providing suggestions and comments, (k) MWRPRC making the decision according to review comments of the committee, records of site survey and hearing, and suggestions of local water resources management departments, (l) MWRPRC issuing an approval letter or the reasons for rejecting the water-related schemes proposed in the WRA report to the construction unit who may legally apply for re-approval, and (m) the water resources management departments supervising design, construction and operation of the inland NPPs according to the WRA report and the approval documents if the issued file is an approval one. Figure 2 shows the flow process chart of TSWM for NPPs in inland China.

\subsection{Main tasks of two-step water management}

The main tasks of TSYM for NPPs in inland China should mainly consist of the following five tasks: i) Carrying out EIA management for a NPP in inland China

One of the main tasks of TSWM is carrying out EIA management in the stage of feasibility study.

According to the Environmental Impact Assessment Law of the People's Republic of China (the President of the People's Republic of China, 2003), the construction unit of an inland NPP shall entrust a qualified agency with the task of EIA. Then the qualified agency should develop the assessment and compile the EIA report. As for water resources, the EIA report of an inland NPP mainly addresses the radioactive concentration of receiving water body and its mitigation measures. Furthermore, public participation is to be conducted by the methods of holding hearings, holding colloquia and so on to ask for the public opinions. Finally, the MEPPRC shall make an administrative decision based on the EIA report and public opinions.

The first step of TSWM (i.e. EIA management) for NPPs in inland China is conducted in accordance with the Environmental I mpact Assessment $L$ aw of $t$ he People's Republic of China and has been performed in China. However, the second step of TSWM (i.e. WRA management) for NPPs in inland China is still in the initial and exploration period. Therefore, main tasks of it are proposed specifically as following.

ii) Stating the requirements for completing the WRA report

According to Management A pproaches of $W$ ater resources assessment of $C$ onstruction $P$ rojects and Management $A$ pproaches of $W$ ater $r$ esources assessment Qualification of $C$ onstruction Projects (MWRPRC, NDRCPRC, 2002b), the qualified agency shall carry out the WRA report completion according to the related requirements and regulations. Considering its particular water-related characteristics, proposing special requirements and regulations should be one of the major tasks of the management system of WRA for NPPs in inland China. Water resources management departments should carry out investigations and researches on the issues including current situation of inland NPPs and the water resources management in other countries, control indicators of water use of inland NPPs, low-level radioactive wastewater discharge 


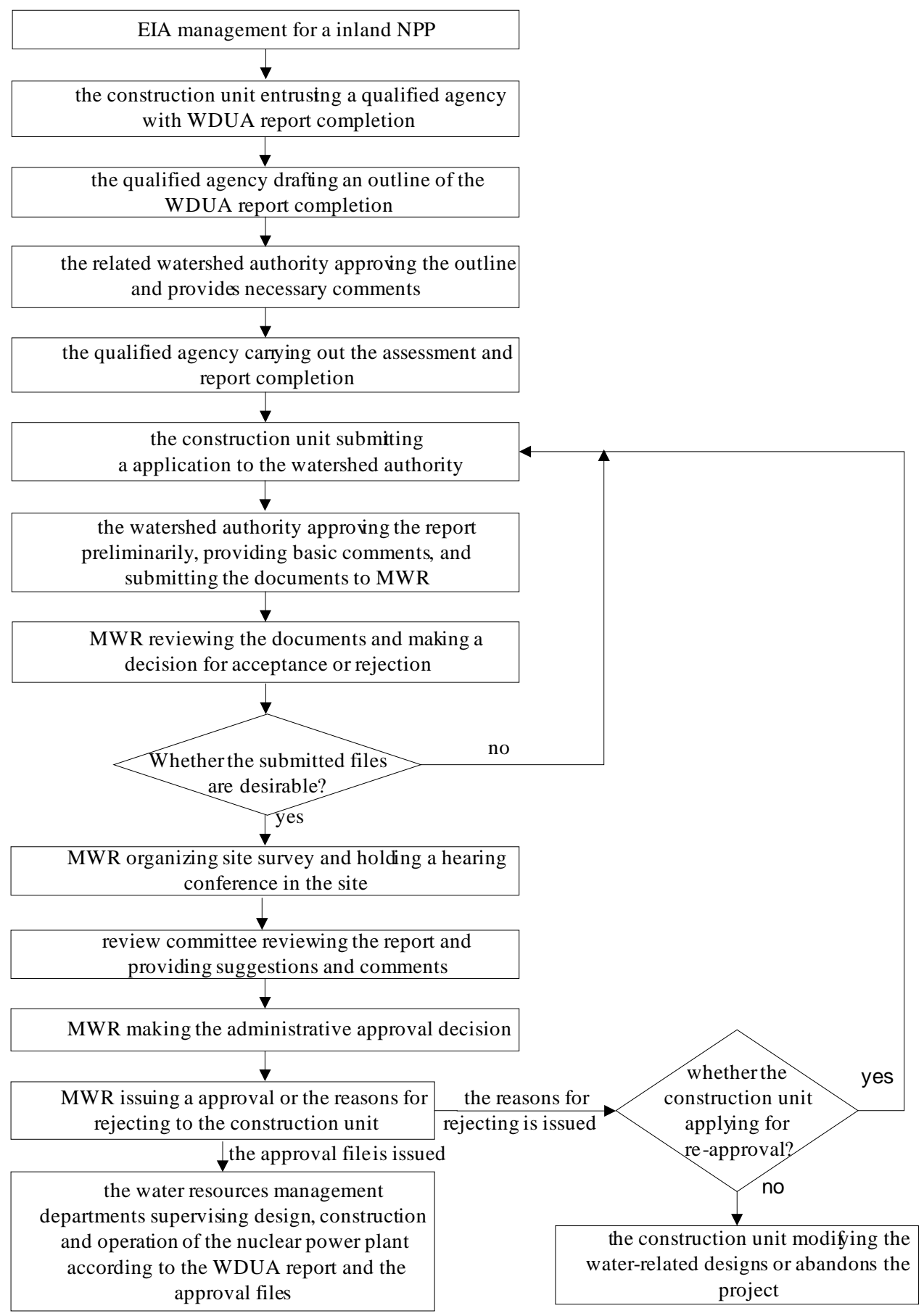

Fig. 2. The flow chart of TSWM for nuclear power plants in inland China.

control of inland NPPs, dilution and diffusion ability of receiving water, the impact of accidents on water resources and the countermeasures, and water resources constraints for inland NPP siting and so on. In the near future, technical standards and guidelines of WRA report completion for inland NPPs needs to be put forward.

iii) Organizing review panels of WRA reports

According to Administrative $P$ ermission $L$ aw, Management $A$ pproaches of $W$ ater $r$ esources 
assessment of Construction Projects, as well as Management $R$ egulations of $R$ eviewing of Water resources assessment Reports for Construction Projects (Trial), the water resources management departments shall organize the outline and report review of a NPP. MWRPRC or the watershed authority shall identify more than seven experts from the expert database established by MWRPRC to form a review committee. Background, education, experiences and achievements should be mainly considered in expert selection. As far as current expert database established by MWRPRC is concerned, most of the experts are major in waterrelated areas such as hydrology, hydrogeology, water resources management, and water pollution control. In future, experts should understand the water-related processes of construction and operation of NPPs. Moreover, nuclear experts need to be involved in the expert database. Among the experts of a review committee, one of them should be appointed as the director to preside over the review meeting. Major duties of the director should include: (a) hosting the review meeting, (b) carrying out principal technical review of a WRA outline or a report, (c) declaring the review comment achieved by the committee, (d) signing the review comment, and (e) taking technical responsibility for the review comment. In the review meeting, committee members should express their opinions on water-related schemes proposed in an outline or a report, and give suggestions on water withdraw, water consumption, wastewater discharge, as well as water conservative measures for improving the report. The opinions and suggestions should be significant references for the following administrative approval.

iv) Carrying out administrative approval of WRA reports

According to the laws and regulations mentioned above, administrative approval of a WRA report for a NPP in inland China is an official decision-making which give a government's opinion on the water-related schemes proposed in the report. The decision should be based on the requirements of state laws and regulations, the characteristics of a inland NPP, the impact on the water body (including the intake and receiving ones) and other water users, rationality and feasibility of water resources conservative and mitigation measures, the comment of the review committee, the suggestions of local water resources management departments, the opinions of other water users of local watersheds, and other related conditions. In China, watershed authorities should take the responsibilities of outline approving as well as preliminary report approving of NPPs, and then MWRPRC should approve reports and make final decisions. The emphases of administrative approval should be the rationalities, feasibilities and reliabilities of the schemes of water withdraw, water consumption, wastewater discharge, and water resources protection. MWRPRC and watershed authorities shall give approval documents within 20 days if the submitted files are well prepared. Administrative approval will ensure the legality and validity of WRA management, and promote construction units to fulfill their obligations of water resources protection actively.

v) Supervising and monitoring the enforcement of WRA reports and approval documents

According to Management $A$ pproaches of $W$ ater resources as sessment of $C$ onstruction $P$ rojects, Management A pproaches of $W$ ater $r$ esources assessment Qualification of Construction Projects, and Management $R$ egulations o $f R$ eviewing $o f$ Water resources assessment Reports for Construction Projects (Trial), after the WRA report of a NPP is approved by MWRPRC, the construction unit can apply for water withdraw permission and intake water from the specified water body. Design, construction and operation of the power plant should be consistent with the WRA report and approval document, which should be also supervised by water resources management departments. Methods of supervising may include remote monitoring, site inspection, post-assessment and so on.

\subsection{Management tools of two-step water management}

i) Making laws, regulations and standards Legislation should be a legal method to facilitate the TSWM for NPPs in inland China. Besides the Environmental Impact Assessment Law of the People's Republic of China, TSWM for NPPs in inland China also involves regulations relating to wastewater discharge, such as Integrated $W$ astewater Discharge Standard (GB 8978-1996) (MEPPRC, GAQSIQPRC, 1996), Environmental Quality St andardf or Surface Water (GB 3838-2002) (MEPPRC, GAQSIQPRC, 2002) and so on. Particularly, in 2005, MWRPRC issued 
Requirements of $W$ ater $r$ esources a ssessment $R$ eports for Construction $P$ rojects (SL/Z322-2005) (i.e., the annex of Management A pproaches of Water resources assessment of Construction Projects). It gives specific requirements on technical levels, scopes, contents, and approaches for the two steps of TSWM. But none of them is specifically for NPPs in inland China. Different from other construction projects, NPPs in inland China involves not only huge fresh water consumption, but also the discharge of radioactive wastewater and cooling water. So legislation on WRA for NPPs in inland China is urgently needed. In the near future, water resources management departments should issue a special technical guideline in which the scope and depth of assessment, the content and focus of analysis, the indicators of rationality analysis of water withdraw and consumption, as well as the methods of impact estimation of water withdraw and wastewater discharge are specified.

ii) Field trip and site survey

Field trip and site survey are helpful for decision makers and review experts to investigate the planned sites of NPPs and identify potential risks and water-related problems. By this ways, they can obtain direct and useful information about current situations of water resources in local area. At the same time, they can capture the opinions of local water resources management departments through acquiring. So field trip and site survey should be the tools to support management for NPPs in inland China. Field trip and site survey should focus on issues related to water withdraw and radioactive discharge, such as water withdraw sites, wastewater treatment facilities, locations of discharge outlets, current situation of water resources of intake and receiving water bodies, and the public's perception. Meanwhile, records, photographs, videos about the processes should be preserved. Figure 3 shows the process of field trip and site survey.

iii) Public participation

Beside for industry, water is also an essential resource for residents' living. Water withdraw and consumption of a NPP in inland China would greatly impact on other water users. At the same time, discharge of wastewater threaten and may adversely affect public health. Particularly, under accident conditions, middle or highlevel radioactive wastewater may be released to vicinal water bodies and cause disastrous effects on sources of drinking water. Thus, public participation should be an important process and significant tool for TSWM management. Public's opinions need to be taken in the procedures of decision making and final approval (or rejection). In the site, holding a hearing, a legal way of public participation, should be necessary. It provides an opportunity for interested people and organizations to express their opinions, participate in WRA management, protect their interests, and provide decision support for approval authorities.

iv) Decision-making

Decision-making, involving report review and administrative approval, should be a crucial process of TSWM management. For the first step of TSWM, it should follow the E nvironmental I mpact A ssessment Law of the P eople's $R$ epublic of $C$ hina. As for the second step of TSWM, it should include three phases. Firstly, a related watershed authority should approve the outline of a WRA report completion and the WRA report primarily. Secondly, the review committee should make a decision whether the report is qualified from the technical point of view. The review committee should work as a third-party organization to the construction unit and approval authorities, which makes the decisionmaking process scientific and democratic. Thirdly, the decision-making process of administrative approval should be organized and carried out by MWRPRC. It should follow the principle of "government-oriented" considering that it affects public’s interests.

\subsection{Reporting requirements of two-step water management}

For TSWM approach, EIA and WRA reports are important considering that they reflect the impacts of the construction and operation of NPPs on water resources as well as their mitigation schemes. EIA report compiling should comply with the Environmental Impact A ssessment L aw of the P eople's Republic of China and Technical $G$ uidelines $f$ or E nvironmental Impact A ssessment (MEPPRC, 2011). Moreover, detailed requirements for completing a WRA report for an inland NPP project are presented as follows (Table 2).

i) General description

In this part, general information related to the report needs to be described such as background information, 
main purposes, major tasks, assessment scope, and target years.

ii) Executive summary social economy of local area, (b) quantity, dynamics, and temporal-spatial distribution of water resources, (c) water quality, the relevant database, and the assessment methods, (d) current situation of water consumption, (e)

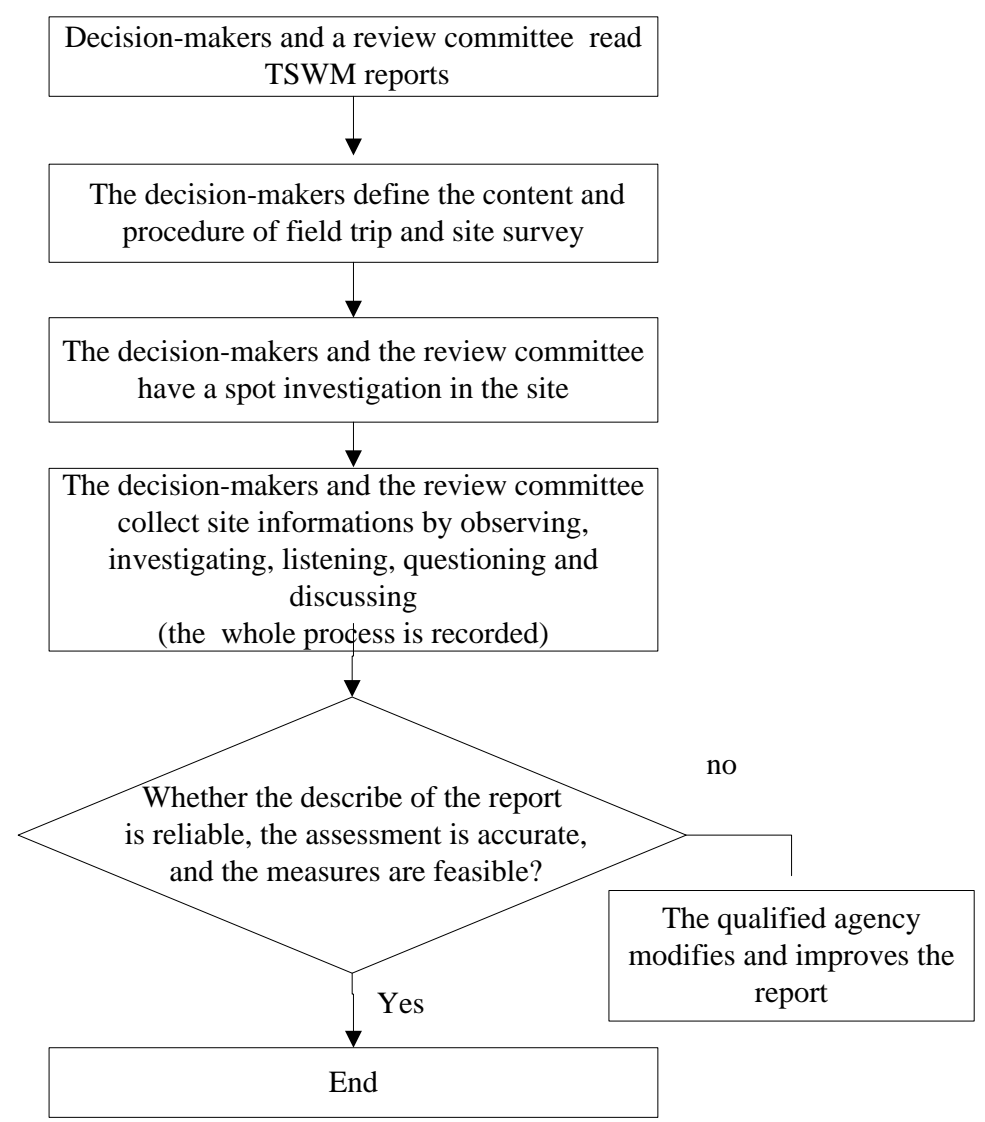

Fig. 3. The process of field trip and site survey.

In this part, basic information of the NPP needs to be briefly presented, such as: (a) name, investment source, and scale, (b) site, floor space, land use, and implemental suggestions, (c) necessary approval documents by other related authorities, (d) water withdraw schemes including possible sources of water resources, water levels of intake water bodies, quantity of intake water, quality of intake water, temperature of intake water, water withdraw location, water withdraw inlet setting, and water consumption techniques and processes, and (e) wastewater discharge schemes including the radioactive concentration of wastewater, wastewater quantity, discharge methods, and discharge location and outlet setting.

iii) Current situation of water resources in local area This part should mainly include the following six aspects: (a) basic information of physical geography and major problems of water consumption, and f) attached drawings and graphs.

iv) Water sources assessment

This part should mainly include water quantity and quality assessment of water sources. Reasonable structure and scale of economic development should be also proposed based on current situation of water resources in local area. Water quality and the related requirements should be discussed. Also, reasonable locations of water withdraw need to be justified and determined. Surface water sources assessment should focus on reliability of water sources based on hydrological serial materials. In China, water sources of construction projects include surface water, groundwater and unconventional water. But for NPPs, groundwater and unconventional one shouldn't be involved (even as auxiliary ones) considering of huge fresh water consumption. If surface water in site area is 
inadequate, a construction unit should relocate the site rather than use groundwater or unconventional one as water resources.

v) Rationality analysis of water withdraw and consumption establishment of water consumption indicators based on Assessment I ndicators and Calculation Methods $f$ or Industrial $W$ ater (CJ 42-1999), Evaluating $g$ uide $f$ or waters avinge nterprises (GB/T 7119-2006) (GAQSIQPRC, 2006) and other relevant standards, (d) rationality analysis of water consumption, (e) analysis

Table 2. Requirements for completing TSWM reports.

\begin{tabular}{|c|c|c|c|}
\hline Step & No. & Part & Requirements \\
\hline I & 1 & EIA reports & $\begin{array}{l}\text { comply with the Environmental Impact A ssessment Law of the People's Republic of } \\
\text { China and Technical Guidelines for Environmental Impact Assessment }\end{array}$ \\
\hline \multirow{10}{*}{ II } & 1 & General description & $\begin{array}{l}\text { describing background information, main purposes, major tasks, assessment scope, } \\
\text { and target years of the report }\end{array}$ \\
\hline & 2 & Executive summary & introducing basic information about the project \\
\hline & 3 & $\begin{array}{l}\text { Current situation of } \\
\text { water resources in local } \\
\text { areas }\end{array}$ & $\begin{array}{l}\text { analyzing basic information of water resources in local areas, current situation of } \\
\text { water resources utilization }\end{array}$ \\
\hline & 4 & $\begin{array}{l}\text { Water sources } \\
\text { assessment }\end{array}$ & assessing the quantity and quality of the water sources \\
\hline & 5 & $\begin{array}{l}\text { Rationality analysis of } \\
\text { water-draw and } \\
\text { utilization }\end{array}$ & $\begin{array}{l}\text { evaluating impacts of water-draw and utilization on regional water resources } \\
\text { allocation, other water users, and even regional water utilization structure (As for an } \\
\text { inland NPP with } 4 \text { AP1000, water-draw amount should be no more than } 1.2 \mathrm{~m}^{3} / \mathrm{s} \cdot \mathrm{GW} \text {, } \\
\text { total water use amount should be no more than } 55 \mathrm{~m}^{3} / \mathrm{s} \cdot \mathrm{GW} \text {, water consumption } \\
\text { amount should be no more than } 1.0 \mathrm{~m}^{3} / \mathrm{s} \cdot \mathrm{GW} \text {, and reuse rate of water resources should } \\
\text { be no less than } 97.5 \% \text {.) }\end{array}$ \\
\hline & 6 & $\begin{array}{l}\text { Impact analysis of } \\
\text { wastewater discharge }\end{array}$ & $\begin{array}{l}\text { describing the wastewater discharge system and its components, assessing the } \\
\text { rationality of the outlet setting, discussing the pollutants in discharged wastewater, } \\
\text { analyzing impact of wastewater discharge on the receiving water bodies, and } \\
\text { simulating the temporal variation of pollutant discharge and the spatial-temporal } \\
\text { variations of pollutants (As for an inland NPP with } 4 \text { AP1000, wastewater discharge } \\
\text { amount should be no more than } 0.35 \mathrm{~m}^{3} / \mathrm{s} \cdot \mathrm{GW} \text { and the flow of the receiving river } \\
\text { should be no less than } 57.1 \mathrm{~m}^{3} / \mathrm{s} \text {.) }\end{array}$ \\
\hline & 7 & $\begin{array}{l}\text { Impact analysis of the } \\
\text { project on the regional } \\
\text { water resources and } \\
\text { other water users }\end{array}$ & $\begin{array}{l}\text { analyzing the effects of water-draw and utilization on regional water resources } \\
\text { allocation and water intake of other users, discussing the adverse impact of radioactive } \\
\text { wastewater discharge on drinking water quality and other water users, and proposing } \\
\text { necessary compensation measures preliminarily }\end{array}$ \\
\hline & 8 & $\begin{array}{l}\text { Water conservative } \\
\text { measures }\end{array}$ & $\begin{array}{l}\text { proposing water conservative measures, and analyzing the applicability and feasibility } \\
\text { of the engineering measures for emergency }\end{array}$ \\
\hline & 9 & $\begin{array}{l}\text { Mitigation schemes for } \\
\text { the adverse impact on } \\
\text { other water users }\end{array}$ & $\begin{array}{l}\text { Presenting compensation measures in detail, estimating the mitigation effects and the } \\
\text { final impacts on other water users quantitatively }\end{array}$ \\
\hline & 10 & Conclusions & $\begin{array}{l}\text { giving a comprehensive evaluation on the schemes of water-draw, water utilization } \\
\text { and wastewater discharge of the project }\end{array}$ \\
\hline
\end{tabular}

values for TSWM

In this part, impacts of water withdraw and consumption on other water users, regional water resources allocation, and even regional water consumption structure need to be assessed. The following seven aspects should be contained, including: (a) water withdraw amount and its rationality analysis, (b) water balance analysis, (c) of water-saving measures, and (f) analysis of the impact of surface water withdraw. According to the standards mentioned above, Construction St andard of N PPS (Exposure Draft) (China Power Engineering Consulting Group Corporation, 2011), as well as design documents of inland AP1000 NPPs in China (CJWRC, 2009; 
Wuhan University, 2009a; Wuhan University, 2009b) and the USA (USNRC, 2009), water consumption indicators of inland NPPs with AP1000 reactors and the recommended values for WRA are shown in table 3. As far as an inland NPP with 4 AP1000 reactors (as the three pioneering ones in China) is concerned, water be demonstrated. Reasonable wastewater discharge schemes and suggestions for mitigation shall be proposed. Considering that wastewater of a NPP includes radioactive one and non-radioactive one, the former shall attract special attention and the latter may be controlled similar to that of a thermal power plant.

Table 3. Water utilization indicators of an inland NPP with AP1000 reactors and recommended.

\begin{tabular}{|c|c|c|c|c|c|c|c|}
\hline \multirow[b]{2}{*}{ No. } & \multirow[b]{2}{*}{ Indicator } & \multicolumn{4}{|c|}{ Design values of NPPs } & \multirow{2}{*}{$\begin{array}{l}\text { Values proposed in } \\
\text { Construction } \\
\text { Standard of NPPs } \\
\text { (draft) }\end{array}$} & \multirow{2}{*}{$\begin{array}{l}\text { Recommended } \\
\text { value } \\
\text { for TSWM }\end{array}$} \\
\hline & & $\begin{array}{c}\text { Taohuajiang } \\
\text { NPP }\end{array}$ & $\begin{array}{l}\text { Dafan } \\
\text { NPP }\end{array}$ & $\begin{array}{l}\text { Pengze } \\
\text { NPP }\end{array}$ & $\begin{array}{l}\text { Vogtle } \\
\text { NPP }\end{array}$ & & \\
\hline 1 & $\begin{array}{c}\text { Total water use } \\
\text { amount }\left(\mathrm{m}^{3} / \mathrm{s} \cdot \mathrm{GW}\right)\end{array}$ & 54.35 & 60.33 & 54.25 & 54.07 & - & $\leq 55$ \\
\hline 2 & $\begin{array}{l}\text { Water-draw amount } \\
\left(\mathrm{m}^{3} / \mathrm{s} \cdot \mathrm{GW}\right)\end{array}$ & 1.24 & 1.27 & 1.16 & 0.96 & 1.2 & $\leq 1.2$ \\
\hline 3 & $\begin{array}{l}\text { Water consumption } \\
\text { amount }\left(\mathrm{m}^{3} / \mathrm{s} \cdot \mathrm{GW}\right)\end{array}$ & 0.88 & 0.92 & 0.81 & 0.72 & 1.0 & $\leq 1.0$ \\
\hline 4 & $\begin{array}{l}\text { Reuse rate of water } \\
\text { resources (\%) }\end{array}$ & 97.72 & 97.59 & 97.90 & 98.23 & - & $\geq 97.5$ \\
\hline 5 & $\begin{array}{c}\text { Wastewater discharge } \\
\text { amount }\left(\mathrm{m}^{3} / \mathrm{s} \cdot \mathrm{GW}\right)\end{array}$ & 0.36 & 0.35 & 0.36 & 0.24 & - & $\leq 0.35$ \\
\hline
\end{tabular}

withdraw and consumption amounts are recommended as no more than $1.2 \mathrm{~m}^{3} / \mathrm{s} \cdot \mathrm{GW}$ for water withdraw, no more than $55 \mathrm{~m}^{3} / \mathrm{s} \cdot \mathrm{GW}$ for total water use, no more than $1.0 \mathrm{~m}^{3} / \mathrm{s} \cdot \mathrm{GW}$ for water consumption, and no less than $97.5 \%$ for reuse rate of water resources.

vi) Impact analysis of wastewater discharge

In this part, the wastewater discharge system and its components shall to be described. Also, the rationality of the outlet setting needs to be assessed. The concentrations, total amounts, discharging standards, temporal and spatial variations, and compliance rates of pollutants need to be depicted. Whether wastewater discharge meets the total allowable quota and the requirements of receiving water bodies also needs to be assessed. The quantitative and cumulative impacts of wastewater discharge on water resources under normal working conditions should be analyzed. The rationalities of low-level radioactive wastewater discharge scheme (under normal working conditions) as well as medium or high-level radioactive wastewater discharge scheme (under accident conditions) shall also
Particularly, impacts of medium and high-level radioactive wastewater discharge on water resources security under nuclear leakage accident conditions need to be evaluated.

Take an AP1000 reactor as an example, wastewater discharge amount should be no more than 0.35 $\mathrm{m}^{3} / \mathrm{s} \cdot \mathrm{GW}$ (see table 3 ). The design source terms of tritium and other liquids are $3.74 \times 10^{13} \mathrm{~Bq} / \mathrm{y}$ and $9.46 \times 10^{10} \mathrm{~Bq} / \mathrm{y}$ respectively. In this part, a safety factor of 1.2 can be adopted, so those for an NPP with 4 AP1000 units are listed in table 4. China's standards for radioactive pollutant discharge of inland NPPs also are also presented in table 4. According to the discharge amounts and standard values, the minimum flow of the receiving water is deduced and the recommended one is $57.1 \mathrm{~m}^{3} / \mathrm{s}$ (see table 4 ). In addition, for riverside NPPs, outlets should be near main-flow areas of rivers, chutedischarge mode should be adopted, and discharging effluents into floodplains should be prohibited. Besides annual discharge control, quarterly and monthly ones also need to be controlled. That's to say, the discharge amounts of per quarter and per month should be no

Table 4. Wastewater discharge indicators for a NPP with 4 AP1000 units in inland China.

\begin{tabular}{|c|c|c|}
\hline Indicators & Radioactive Pollutant & Value \\
\hline $\begin{array}{l}\text { Designed discharge amount of per unit (Bq/y) } \\
\text { (Ontario Power Generation, 2009) }\end{array}$ & $\begin{array}{c}\text { liquid } \mathrm{H}-3 \\
\text { sum of other liquids }\end{array}$ & $\begin{array}{l}3.74 \times 10^{13} \\
9.46 \times 10^{9}\end{array}$ \\
\hline Discharge amount of a NPP with a safety factor of $1.2(\mathrm{~Bq} / \mathrm{y})$ & $\begin{array}{l}\text { liquid } \mathrm{H}-3 \\
\text { sum of other liquids }\end{array}$ & $\begin{array}{l}1.80 \times 10^{14} \\
4.54 \times 10^{10}\end{array}$ \\
\hline $\begin{array}{l}\text { Concentration of the receiving water downstream } 1 \mathrm{~km} \\
\text { from the origin of sewage discharge }(\mathrm{Bq} / \mathrm{L})\end{array}$ & liquid $\mathrm{H}-3$ & $\leq 100$ \\
\hline $\begin{array}{c}\text { (MEP, General Administration of Quality Supervision, Inspection, and } \\
\text { Quarantine of the PRC, 2011a \& 2011b) }\end{array}$ & sum of other liquids & $\leq 1$ \\
\hline $\begin{array}{l}\text { Required minimum flow of receiving water to meet the concentration } \\
\text { standard of the pollutant (hỉ/s)ished by Atlantis Press }\end{array}$ & $\begin{array}{l}\text { liquid } \mathrm{H}-3 \\
\text { sum of other liquids }\end{array}$ & $\begin{array}{l}57.1 \\
1.44\end{array}$ \\
\hline $\begin{array}{l}\text { Copyright: the aythors } \\
\text { Recommended value of minimum flow of receiving waferr }\left(\mathrm{m}^{2} \mathrm{~s}\right)\end{array}$ & 57.1 & \\
\hline
\end{tabular}


more than half and one fifth of the approved annual one (MEPPRC, GAQSIQPRC, 2011a).

vii) Impact analysis of the NPP on the regional water resources and other water users

In this part, the effects of water withdraw and consumption on regional water resources allocation as well as water intake of other users need to be analyzed. The adverse impact of radioactive wastewater discharge on drinking water quality and other water users shall be evaluated in detail. Considering the large amount of water consumption of an inland NPP, necessary compensation measures shall be proposed preliminarily for people and organizations those are affected.

viii) Water conservative measures

In this part, water conservative measures need to be proposed and assessed. Particularly, applicability and feasibility of the engineering measures for any emergencies shall to be presented. The construction unit and qualified agency shall follow principles of strengthening water reuse, reducing water consumption, and ensuring water security.

ix) Mitigation schemes for the adverse impact on other water users

Even if necessary measures are adopted, water withdraw and wastewater discharge would still affect the interests of other water users. In the part, compensation measures need to be proposed in detail. The mitigation effects of compensation measures and the final impacts on other water users need to be quantitatively evaluated.

\section{$\mathrm{x})$ Conclusions}

In this part, the entire assessment work needs to be summarized and a comprehensive evaluation on the schemes of water withdraw, water consumption and wastewater discharge of the power plant needs to be presented. This would provide a scientific support for WRA administrative approval and water withdraw permission. In this part, the following key points need to be covered: (a) the attitude to construction and operation of the NPP based on current situation of water resources in local area, (b) the water allocation plans and strategies of the corresponding watershed or region, (c) the guarantee rate of water withdraw sources, (d) the total water demand of the power plant as well as the rationalities of water consumption and saving potentials, (e) the amount, pollutant concentration and discharge mode of wastewater, (f) the impact of water withdraw and wastewater discharge on other water users and its conservative measures, and (g) suggestions for WRA approval and supervision.

Take the three pioneering NPPs in inland China as examples. According to the current design, they will be located in the vicinity of inland water bodies in the Yangtze River watershed. Yangtze River is the largest river in China and significant for water supply to municipal, agricultural and industrial sectors. So in the WRA reports, water sources, quantities of intake water, water use efficiencies, wastewater discharge, hydrodynamic conditions of receiving water bodies, adverse impacts on local water bodies and other water users, mitigation schemes should be the emphases.

\section{Enhancement of Water Management for Nuclear Power Plants through TSWM}

As for water management for nuclear power plants in inland China, it can be enhanced through TSWM approach by the following ways.

\section{i) Advancing involvement time}

With regard to current water management for other construction projects, EIA and WRA will be carried out when the site of the project is confirmed. But it is not suitable for NPPs in inland China. Because once the site of a NPP is confirmed, a huge amount of fund and manpower will be invested and lots of water-related issues will be identified. Meanwhile, the total allowable quota of receiving water bodies, local water demands, and watershed management strategies is also confirmed. On one hand, it is difficult for assessors and water resources management departments to propose negative opinions on a confirmed site location for huge investments and manpower in preliminary phases. On the other hand, current situation of water resources may not be suitable and potential risks to water bodies should be also further identified. That is an important reason why the three pioneering plants are stagnant nowadays. Take Hunan Taohuajiang NPP for example, the total expense of the preliminary actions after siting was around 600 million dollars (Li, 2012). Nowadays, the huge money has been spent, but the WRA management has not involved. So the inland NPP has to be suspended considering its serious influence on water 
resources and its probable nuclear leakage accidents (even with very extremely low probability).

In future, water management for NPPs should be involved at the preliminary phases (planning and siting ones) of an inland NPP. Necessary regulations and policies need to be put forward and implemented to guarantee it. Thus, the water resources management departments can have a full understand of the NPP and give contemporaneous suggestions on the designs related to water resources, such as the siting of a plant, the distance between the plant and water bodies, the allowable pollution carrying capacity of the receiving river and so on.

ii) Strengthening the effectiveness of administrative approval

The first step of TSWM is required by the Environmental Impact Assessment Law of the People's Republic of China and administrative approval of it is legal and effective. However, administrative approval of the second step needs to be strengthened. Nowadays, local governments (including provincial, municipal and county ones) support inland NPPs strongly due to the huge stimulation of local economy. Therefore, they and construction units are not quite willing to carry out WRA considering that it may delay or reject NPPs and associated investments. Meanwhile, the authority of water resources management departments, particularly watershed authorities, is inadequate in China. So in the future, the effectiveness of administrative approval of TSWM needs to be further strengthened. Specific laws should be legislated for WRA and administrative approval of WRA should be enforced at the preliminary phases of a NPP project. In this way, if water resources condition in the local area is not appropriate for supporting the operation of an inland NPP, water resources management departments could require the construction unit to adjust the original site.

iii) Improving the technical level of assessment reports Till now, there are several technical issues need to be tackled. For example, (a) how to accurately determine the minimum safe distance between an inland NPP and the nearby water bodies, (b) what are the typical transport and decay processes of radioactive substances in receiving water bodies, and (c) and what would be the cumulative effects of radioactive substances on aquatic organisms? Such questions are complicated and need to be answered on an interdisciplinary basis (e.g., hydrology, radiology, and biology).

At the same time, there is a lack of special technical guidelines and standards, which poses challenges to assessors. Especially for the second step of TSWM, it concerns several unprecedented and uncertain technical issues including those mentioned above. Therefore, MWRPRC and the related watershed authorities have supported a series of research efforts in studying the necessary standards, guidelines, and regulations. For example, research on analyzing the impacts of radioactive wastewater of NPPs on aquatic organisms has been carried out. Based on it, appropriate models and monitoring methods are expected to be proposed. In the near future, a number of technical training programs should be provided for assessors to enhance their capabilities in conducting WRA for inland NPP projects. Moreover, a series of management measures also need to be adopted. For example, water resources management departments should take reward and penalty measures, by which the superior qualified agencies will be encouraged while the inferior ones will be discarded. At the same time, technical exchange among qualified agencies needs to be carried out, which will strengthen the responsibility of assessors and improve their abilities.

iv) Enhancing the ability of review committees Because inland NPPs is a kind of new projects in China, reviewers included in the existing expert databases may not be well familiar with all aspects of the construction and operation processes of inland NPPs. As for TSWM, China's environmental protection and water resources management departments should make efforts in enhancing the ability of reviewers. Especially for the second step of TSWM, it is necessary to invite nuclear experts to take part in the technical review due to the lack of experts majored in nuclear science and engineering. The cooperation between water resource professionals and nuclear ones (such as experts of National Nuclear Safety Administration of the PRC) needs be also strengthened. Moreover, further communication between review committee and public (especially water users of receive water bodies) shall be developed considering that review committees have the responsibilities to reflect the public interest effectively and incorporated it into decision-making processes. 
v) Improving public participation

As for TSWM, MEPPRC (2008) has released Implementing Measures of Public Participation o $f$ Environmental I mpact A ssessment f or nuc lear p ower plants (Exposure D raft), which gives general requirements, implementing regulations and organizational forms of public participation in different phases of NPPs for the first step of TSWM. However, that of the second step of TSWM should be improved considering of its close relationship to water resources and great public concerns. For designed receiving water bodies of radioactive wastewater in inland China, almost all of the lower reaches of them are with drinking water sources. Radioactive wastewater discharge also has various adverse impacts on human health, water quality and aquatic ecosystems. In future, model prediction needs to be used to reflect the sensitivity of public concerns. Public participation is an effective way to resolve water disputes, improve the effectiveness of decision-making, and enhance the democracy of WRA management. Considering that, water resources management departments shall increase the degree of public participation in WRA through various ways. In the process of the second step of TSWM, the information of a NPP and its impacts on water resources and other water uses needs to be released in time. In the WRA reports, the forms and approaches of public participation need to be specified. With the enhancement of the transparency of WRA management, the public's misunderstanding on any NPPs will be reduced. In the foreseeable future, posting notice in local areas, releasing notification in web sites, as well as holding hearings and colloquia shall be developed. Through the above measures, the public can get necessary information conveniently. Public opinions shall be taken into account when qualified agencies complete the chapters of impact analysis of a NPP on the regional water resources and other water users.

\section{Conclusions}

Nuclear power is an important energy source to deal with climate change and energy shortage. Nowadays, a number of inland nuclear power plants (NPPs) are operated or planned to be constructed across the world. Take China for example, construction of three pioneering inland NPPs (Hunan Taohuajiang NPP, Hubei Dafan NPP, and Jiangxi Pengze NPP) may be started in a few more days. It poses great challenges to
China's water resources management due to large quantity of fresh water consumption and radioactive wastewater discharge. Thus, it is desired that an effective water-management approach for such projects shall be conducted in China. A two-step watermanagement approach (TSWM), proposed in this article, presents a comprehensive and feasible management approach of water withdraw, water consumption, wastewater discharge of such kind of construction projects. In this research, the flow process of TSWM for NPPs in inland China was proposed. It should include EIA management, entrusting the work of WRA report completion, drafting an outline, a watershed authority approving the outline, report completion, the watershed authority approving the report preliminarily, site survey and hearing, review committee reviewing the report, final administrative approval, and regulating. In addition, it was put forward that main tasks of the management system should consist of carrying out EIA management for a NPP in inland China, proposing the requirements for report completion, organizing report review, carrying out administrative approval, and supervising the enforcement of approval documents. Moreover, management tools of TSWM for NPPs were also presented. It may contain constituting laws and standards, field trip and site survey, public participation, as well as decision-making. As far as the decisionmaking is concerned, "three-step process" was suggested to be taken besides EIA management. The process may contain watershed authority making a decision whether the work outline is appropriate, a review committee making a decision whether the WRA report is qualified, and MWRPRC making a decision whether the water-related schemes proposed in the report is reasonable and feasible. Furthermore, detailed requirements for completing TSWM reports for an inland NPP were also proposed. EIA report compiling should comply with the relevant laws and technical guidelines. A WRA report for an inland NPP is proposed to cover general description, executive summary and conclusions. It also shall depict current situation of water resources and water sources, analyze the rationality and feasibility of water withdraw, assess water consumption and wastewater discharge of the project, evaluate the impact of water withdraw and wastewater discharge on water environment and other water users, and propose water conservative measures and mitigation schemes for adverse impacts. As far as 
an inland NPP with 4 AP1000 reactors (as the three pioneering ones in China) is concerned, water withdraw and consumption amounts are recommended as no more than $1.2 \mathrm{~m}^{3} / \mathrm{s} \cdot \mathrm{GW}$ for water withdraw, no more than 55 $\mathrm{m}^{3} / \mathrm{s} \cdot \mathrm{GW}$ for total water use, no more than $1.0 \mathrm{~m}^{3} / \mathrm{s} \cdot \mathrm{GW}$ for water consumption, no less than $97.5 \%$ for reuse rate of water resources, and no more than $0.35 \mathrm{~m}^{3} / \mathrm{s} \cdot \mathrm{GW}$ for wastewater discharge. The flow of the receiving river of an inland NPP with 4 AP1000 reactors should be no less than $57.1 \mathrm{~m}^{3} / \mathrm{s}$.

Suggestions for establishing the effective and feasible management for the new kind of projects were provided. TSWM should be involved at the planning and siting phases of an inland NPP. If water resources condition in the local area is not appropriate for supporting a plant operation, water resources management departments should have the right to negative the site. In the future, several researches on safe distance between a NPP and water bodies, transport and decay processes of radioactive substances in receiving water bodies, and cumulative effects of radioactive substances on aquatic organisms should be carried out. Special standards, guidelines, and regulations for the management system should be constituted. Measures such as cooperation and communication between water resources governors and nuclear ones, technical training for assessors, invite nuclear experts to take part in the technical review, as well as reward and penalty measures should be also taken. In addition, public participation needs to be strengthened by the ways of specifying its forms and approaches, releasing information in time, posting notice, releasing notification, as well as holding hearings and colloquia. It is expected that TSWM will become a powerful and effective management method to support sustainable consumption of water resources and security development of nuclear power industry.

\section{Acknowledgements}

This research work was funded by Ministry of Education, Special Items Fund of Beijing Municipal Commission of Education, National Key Scientific and Technological Projects of PRC (2011ZX06004-008) and the Fundamental Research Funds for the Central Universities of PRC (JB2014129). The authors gratefully acknowledge the financial support of the programs and agencies.

\section{References}

Barrie P. Co-benefits of Large-scale Renewables in Remote Australia: Energy Futures and Climate Change. Rangeland Journal, 33(4 SI) (2011) 315325.

Bezdek R. H. Nuclear Power Prospects in the USA: the Continuing Problem of the Waste Issue. Energy \& Environment, 20(3) (2009) 375-385.

China Power Engineering Consulting Group Corporation. Construction Standard of Nuclear Power Plants (Exposure Draft), in Chinese , 2011.

China's State Council. State Council's Decision on Setting Administrative Permission for the Projects with Necessary Administrative Approval, in Chinese, 2004.

China's State Council. Management Regulations of Water withdraw Permission and Water Resources Fee Collection, in Chinese, 2006.

China's State Council. Four Decisions of State Council Concerning the Development of Nuclear Power Industry, in Chinese, 2011.

Dai J. S., Yi Y.G. Condition of Inland Nuclear Power Plant Construction Is Basically Ready. State Grid News, 2010-07-15, in Chinese,2010.

Department of Justice Canada. Canadian Environmental Assessment Act, 2012.

General Administration of Quality Supervision, Inspection, and Quarantine of the PRC, Standardization Administration of the PRC. Evaluating Guide for Water Saving Enterprises (GB/T 7119-2006), in Chinese , 2006.

Hu J. T. President Hu's Speech at 2012 Seoul Nuclear Security Summit, in Chinese, 2012.

CJWRC. Hunan Taohuajiang Nuclear Power Plant Phase I Project $2 \times 1000 \mathrm{MW}$ Units Water resources assessment Report, in Chinese, 2009.

IAEA. Convention on Assistance in Case of a Nuclear Accident or Radiological Emergency. , 1896.

IAEA. Convention on Early Notification of a Nuclear Accident, 1986.

IAEA. Convention on Nuclear Safety, 1994.

IAEA. IAEA International Fact Finding Expert Mission of the Fukushima Dai-ichi NPP Accident following the Great East Japan Earthquake and Tsunami, 2011.

Jasmina V., Dragoljub P. A., Zorka V. Environmental Impact and Cost Analysis of Coal versus Nuclear Power: the U.S. Case. Energy, 45(1) （2012）31-42.

Khamis I., Kavvadias K.C. Trends and Challenges 
toward Efficient Water Management in Nuclear Power Plants. Nuclear Engineering and Design, 248 (2012) 48-54.

Kopytko N., Perkins J. Climate Change, Nuclear Power, and the Adaptation-Mitigation Dilemma. Energy Policy, 39(1) (2011) 318-33.

Lane R., Dagher E., Burtt J., Thompson P. A. Radiation Exposure and Cancer Incidence (1990 to 2008) around Nuclear Power Plants in Ontario, Canada. Journal of Environmental Protection, 4(9) (2013) 888-913.

Li Y. F. Hunan Taohuajiang Nuclear Power Plant Is Suspended and the Cost of the Preliminary Work Is about 6 Hundred Million Dollars. Dongfang Morning Paper, 2012-02-20, in Chinese, 2012.

Ma B., Li J., Han B., Han X. Discussions on Experiences of Environmental Investigation around Inland Nuclear Power Plant. Radiation Protection Bulletin, (5)(2010) 32-37.

Ministry of Environmental Protection of the PRC. "the $12^{\text {th }}$ Five-Year Plan and 2020 Vision of Nuclear Safety and Radioactive Pollution Prevention and Control” Is Approved by State Council. Available at: $<$

http://haq.mep.gov.cn/gzdt/201210/t20121016_2384 21.htm>, in Chinese, 2012.

Ministry of Environmental Protection of the PRC, General Administration of Quality Supervision, Inspection, and Quarantine of the PRC. Integrated Wastewater Discharge Standard (GB 8978-1996), in Chinese, 1996.

Ministry of Environmental Protection of the PRC, General Administration of Quality Supervision, Inspection, and Quarantine of the PRC. Technical Requirements for Discharge of Radioactive Liquid Effluents from Nuclear Power Plant (GB145872011) , 2011a.

Ministry of Environmental Protection of the PRC, General Administration of Quality Supervision, Inspection, and Quarantine of the PRC. Regulations for Environmental Radiation Protection of Nuclear Power Plant (GB6249-2011), 2011b.

Ministry of Environmental Protection of the PRC, General Administration of Quality Supervision, Inspection, and Quarantine of the PRC. Environmental Quality Standard for Surface Water (GB 3838-2002), in Chinese, 2002.

Ministry of Construction of the PRC. Assessment
Indicators and Calculation Methods for Industrial Water (CJ 42-1999), in Chinese,1999.

Ministry of Water Resources of the PRC. Claim on Enhancing Water resources assessment Work of Constructing Projects, in Chinese, 2002.

Ministry of Water Resources of the PRC. Management Regulations of Reviewing of Water resources assessment Reports for Construction Projects (Trial), in Chinese, 2003.

Ministry of Water Resources of the PRC. Guidelines of Water resources assessment for Construction Projects (Trial) (SL/Z322-2005). Beijing: China Water Power Press, in Chinese, 2005.

Ministry of Water Resources of the PRC, National Development and Reform Commission of the PRC. Management Approaches of Water resources assessment of Construction Projects, in Chinese, 2002a.

Ministry of Water Resources of the PRC, National Development and Reform Commission of the PRC. Management Approaches of Water resources assessment Qualification of Construction Projects, in Chinese, 2002b.

National People's Congress of the PRC. Water Law of the PRC, in Chinese, 2002.

National People's Congress of the PRC. Administrative Permission Law of the PRC, in Chinese, 2003.

National Development and Reform Commission of the PRC. Medium and Long-term Development Plan of Nuclear Power (2005-2020), in Chinese, 2007.

Nuclear Energy Institute. Water Use, Electric Power, and Nuclear Energy-A Holistic Approach to Environmental Stewardship, 2009.

Nuclear Safety Authority of France. Act No. 2006-686 Transparency and Security in the Nuclear Field, 2006.

Ontario Power Generation. Plant Parameter Envelope: Concept and Application for OPG New Nuclear at Darlington, 2009.

Parliament of Australia. Water Requirements of Nuclear Power Stations, 2006.

Sovacool B. K. Valuing the Greenhouse Gas Emissions from Nuclear Power: a Critical Survey. Energy Policy, 36(8) (2008) 2950-2963.

The Diet's Fukushima Nuclear Accident Independent Investigation Commission. The Final Report of the Fukushima Nuclear Accident Independent Investigation Commission, 2012.

United States Nuclear Regulatory Commission. 10 CFR 
Part 51-Environmental Protection Regulations for Domestic Licensing and Related Regulatory Functions, 1984.

United States Nuclear Regulatory Commission. Regulatory Guide 4.7: General Site Suitability Criteria for Nuclear Power Stations, 1998.

United States Nuclear Regulatory Commission. Vogtle Electric Generating Plant - License Renewal Application, 2009.

United States Nuclear Regulatory Commission. Backgrounder on Tritium, Radiation Protection Limits, and Drinking Water Standards, 2011a.

United States Nuclear Regulatory Commission. Susquehanna Steam Electric Station Radioactive Effluent Release Report and Offsite Dose Calculation Manual, 2011b.

Wang Q. A Comparison of the Nuclear Options for Greenhouse Gas Mitigation in China and in the United States. Energy Policy, 37(7) (2009) 24872491.

Wang Y. X., Sun T. Y. Life Cycle Assessment of $\mathrm{CO}_{2}$ Emissions from Wind Power Plants: Methodology and Case Studies. Renewable Energy, 43 (2012) 30-36.

Wen J. B. 2012 Report on the Government's Work, Delivered at the Fifth Session of the Eleventh, National People's Congress of the PRC on March 5, 2012, in Chinese, 2012.

Wuhan University of the PRC. Hubei Xianning Nuclear Power Plant Water resources assessment Report, in Chinese, 2009a.

Wuhan University of the PRC. Jiangxi Pengze Nuclear Power Plant Phase I Project 2×1000MW Units Water resources assessment Report, in Chinese ,2009b.

Yan Q., Wang A. J., Wang G. S. Nuclear Power Development in China and Uranium Demand Forecast: Based on Analysis of Global Current Situation. Progress in Nuclear Energy, 53(6) (2011) 742-747.

Yang C. J. A Comparison of the Nuclear Options for Greenhouse Gas Mitigation in China and in the United States. Energy Policy, 39(6) (2011) 30253028.

Yang G., Huang W. J. The Status Quo of China's Nuclear Power and the Uranium Gap Solution.
Energy Policy, 38(2) (2010) 966-975.

Zai R. M. Three Key Factors that Hinder the Development of Nuclear Power Plants in Inland China. NeteaseNews, 2012-10-25, in Chinese, 2012.

Zhang S. L., Ding X. W., Chen Q. W. Management of Water Resources Argumentation for Inland Nuclear Power Plants of China. Beijing: China Water Power Press, 2011.

Zhong J. J. China Restarts Nuclear Power Construction and Inland Projects Won't Be Arranged in the Next Three Years. Beijing News, Available at: < http://news.sina.com.cn/c/2012-1025/023925432152.shtml>, in Chinese, 2012.

Zhou S., Zhang X. L. Nuclear Energy Development in China: A Study of Opportunities and Challenges. Energy, 35(11 SI), 4282-4288, 2010.

Zhou Y., Rengifo C., Chen P. P. Is China Ready for Its Nuclear Expansion? Energy Policy, 39(2) (2011) 771-781. 
Abbreviation list

\begin{tabular}{|c|c|}
\hline Abbreviation & Full name \\
\hline AP1000 & Advanced Passive Pressurized Water Reactor 1000 \\
\hline CDC & China Datang Corporation \\
\hline CGC & China Guodian Corporation \\
\hline CGNPC & China Guangdong Nuclear Power Holding Co. Ltd \\
\hline CHD & China Huadian Corporation \\
\hline CHG & China Huaneng Group \\
\hline CJWRC & Changjiang Water Resources Commission \\
\hline CNNC & China National Nuclear Corporation \\
\hline CPIC & China Power Investment Corporation \\
\hline CPR & Commercial Power Reactor \\
\hline EIA & Environmental Impact Assessment \\
\hline GHG & Greenhouse Gas \\
\hline HTGR & High Temperature Gas-cooled Reactor \\
\hline IAEA & International Atomic Energy Agency \\
\hline MEPPRC & Ministry of Environmental Protection of the PRC \\
\hline MWRPRC & Ministry of Water Resources of the PRC \\
\hline NDRCPRC & $\begin{array}{l}\text { National Development and Reform Commission of the } \\
\text { PRC }\end{array}$ \\
\hline NEAPRC & National Energy Administration of the PRC \\
\hline NPCPRC & National People's Congress of the PRC \\
\hline NPP & Nuclear Power Plant \\
\hline USNRC & United States Nuclear Regulatory Commission \\
\hline PRC & People's Republic of China \\
\hline TSWM & Two-step Water-management \\
\hline WRA & Water resources assessment \\
\hline
\end{tabular}

